\title{
Integration of Environment and Content Knowledge into STEM Education
}

\author{
${ }^{1}$ Marco Scotini and ${ }^{2}$ Hussein Abdullah \\ 1,2 International Economics, Fudan University, Shanghai, China, 200437. \\ ${ }^{1}$ scotini878@gmail.com
}

\author{
Article Info \\ Journal of Computing and Natural Science (http://anapub.co.ke/journals/jens/jens.html) \\ Doi: https://doi.org/10.53759/181X/JCNS202202004 \\ Received 25 May 2021; Revised form 28 June 2021; Accepted 30 September 2021. \\ Available online 05 January 2022. \\ (C)2022 Published by AnaPub Publications.
}

\begin{abstract}
With a central focus on the research question: "What must be done to encourage people to become more E+STEM educated?" this research is based on a Systematic review on ecological knowledge, which is linked to teachers' career growth as well as Environmental Science, Technology, Engineering, and Mathematics (E+STEM) pedagogy. The aim is to identify what instructors must do to improve their experience and credentials as E+STEM-educated people in light of expert views. To disclose expert views, a "mixed method" research approach is utilized in this study, which includes both qualitative and quantitative techniques. The technique employed is exploratory study sequencing, which is a kind of mixed-method study. The Delphi study's initial stage is to gather qualitative data on teachers' professional growth. The quantitative methodology is featured for the phase two of the Delphi research once the data has been analyzed in the first step. Lastly, the ultimate quantitative formulation (third phase) is produced following the data evaluation in the second phase.
\end{abstract}

Keywords - Science, Technology, Engineering, and Mathematics (STEM), Environmental Science, Technology, Engineering, and Mathematics (E-STEM).

\section{INTRODUCTION}

SMET (Science, Mathematics, Engineering and Technology) was NSF's (National Science Foundation) perspective in the early 1990s for abbreviating the disciplines. Resultantly, this abbreviation changed to STEM (Science, Technology, Engineering and Mathematics) to avoid misconceptions. In Germany, the STEM concept, which is getting spread across Europe these times, has been called MINT. STEM learning has been in existence for several years now, but legislators and school authorities have only recently acknowledged its importance. STEM Education's Importance in Science Education STEM education is becoming more and more important as a key idea in scientific education.

STEM is becoming an increasingly important aspect of our lives. When we examine the activities and events which occur daily, it is obvious that they are connected to STEM. As a result, some instructors think that STEM education will prepare students for employment in STEM areas [1]. STEM equip learners with the greatest chances to make sense of things comprehensively by integrating four aspects into a cohesive teaching and learning paradigm. Individual growth is also supported by STEM education. STEM education helps students reach their full potential, develop and enhance their self-efficacy, and integrate socially and academically. Furthermore, STEM education encourages pupils to prioritize the following abilities:

- Understanding of every element of STEM;

- Problem-solving exercises are a great way to improve your problem-solving skills;

- Performing in-depth research and creating in an innovative and competent way;

- Modeling and abstraction, as well as thinking and reasoning;

- Utilizing and developing new technologies in a strategic way;

- $\quad$ gaining an understanding of the importance of STEM;

- Getting and understanding information about STEM, as well as talking about it;

- Collaboration and teamwork are two important aspects of student engagement;

- $\quad$ Developing $21^{\text {st }}$-century abilities; and

- Increasing your ability to innovate.

Many nations are still reforming their industries and educational systems to meet global demands. STEM education is one of the innovations in the field of scientific education. STEM education, according to policymakers, is one of the ideas that are critical for the manufacturing industry to enhance the quality of its workers. While STEM education improves the productivity of the workers, we should also focus on environmental awareness to help preserve natural environment.

Environmental awareness has been a major topic in scientific education throughout its history. In recent years, there has been a rise in the number of studies on the creation of an environmental literacy framework. Understanding, knowledge, attitudes, abilities, evaluation capability, and participation were among the six elements of environmental science. This paper focuses on the E-STEM education, with critical focus on the need for the concept of "environment" in STEM. This research also focuses on Pedagogical Content Knowledge (PCK) and its integration in STEM. In that regard, this paper has 
been organized as follows: Section II reviews the relevant sources regarding E-STEM. Section III introduces the research questions. Section IV presents the methodology and design of the research. Section V presents a critical analysis of the research. Section VI presents the results and discussion. Lastly, Section VII concludes the paper and presents directions for future research.

\section{LITERATURE SURVEY}

T. higuchi in [2] posits that Environmental education involves knowledge, disposition, activities, and engagement. The notion of environment awareness was defined with the emergence of education programs. Knowledge, abilities, affects (sensitivity and/or dispositions), and conduct were the four main components of this idea (personal investment, responsibility, and actions).

R. Chepesiuk in [3] argues that environmental literacy entails environmental knowledge and accountability, as well as the integration of environmental attitudes. Environmental literacy, according to its historical evolution, is defined as the ability to detect and understand the health status of ecological variables and to take suitable action to reserve, reestablish, or enhance that wellbeing. Environmentally literate people, according to experts, can comprehend environments and how they work. Furthermore, they are capable of critically considering the impact of people on ecosystem functioning and environmental concerns. They are also aware of the significance of natural. They are capable to engage in ecological actions and efforts instead of their society due to events and the diversities of the normal ecological settings. Based on other definitions, ecological literacy is the capability to make more decisive decisions concerning the challenges that affect shared resources whereas balancing the cultural principles, economic values, environmental values and public health values

M. Morrone, K. Mancl and K. Carr in [4] also argue that ecological literacy integrates the skillset designated to ecological sociological, economical, and cultural dimensions and problems, as well as the information and skills required to make informed choices and become environmentally and socially responsible. Environmental awareness, on the other hand, is described as a person's understanding, ability, and willingness to make rational decisions that include his/her links to biological ecosystems, society, and future generations. As a result of the literature study, no generally recognized concept of environmental awareness can be found. Despite the fact that the idea of environmental literacy has been around for a long time, its complexity makes it difficult to convey.

According to S. Jorgenson in [5], environmental STEM (E-STEM) literacy is important in scientific education, according to researchers. According to the researchers, our 21st-century economies need a high-quality STEM-educated workforce. These emerging economies provide chances for a diverse variety of fascinating and exciting careers. STEM literacy is defined as having understanding of engineering, mathematics, technology and science. STEM education is critical for those entering the workforce since it is one of the fundamental skills of 21 st-century employees. As a result, the first criterion for STEM literacy is that you are interested in and have a basic knowledge of STEM-related subjects. The following is the objective of STEM:

- To meet the requirements of society for novel technical and systematic advancements;

- To address the financial requirements of public safety; and

- To fulfill individual needs in order to become a contented, competent, and well-informed society.

According to F. Stewart in [6], STEM-literate people can illustrate, define and anticipate the consequences of normal occurrences, understand research journals and pieces given in the popular press and media, and develop their own views regarding the authenticity of academic assertions made in the mainstream press, among other things.

Further study on the concept's foundation and implementation in the curriculum is needed to satisfy current and future expectations. As a result, based on expert views, it is essential to disclose the paradigm of environmental education.

\section{RESEARCH QUESTION}

According to expert views, the primary aim of this study is to identify instructors' involvements and credentials as E+STEM learned people for the promotion of ecological education. Q1: What must be done to encourage people to become more E+STEM educated?

\section{METHODOLOGY}

This study used a mixed-method study approach to discover expert perspectives on the ideology of E+STEM skillset. This analysis integrates both the secondary and primary allowing for a more in-depth evaluation of the research topic. The sequential exploratory plan, a form of mix-method study, was utilized. Findings of qualitative approach are used as the foundation for future quantitative research using an exploratory sequential approach. With respect to scholarly comments, the Delphi technique has been utilized to illustrate the ideology of ecological learning and to define the competency level of ecologically-educated persons. The method is utilized to gather opinions on a certain subject. It's a study method for obtaining a common conclusion by combining expert views in order to solve a complicated issue. This method typically entails a series of questions addressed at specialists, allowing them to express themselves freely without being affected by the viewpoints of others.

Quantitative, qualitative, or mixed-method research may all be used in the Delphi approach. The Delphi method prohibits individuals from having direct conversations with one another, but it allows them to constantly examine the issue via interviews or questionnaires [7]. In instances when there are ideological differences, it is utilized to bring specialists together to reach an agreement. The Delphi research was carried out in three stages in this study, as shown in Figure 1. The data collecting technology, the data gathering, and the analytical techniques were all included in each cycle. 


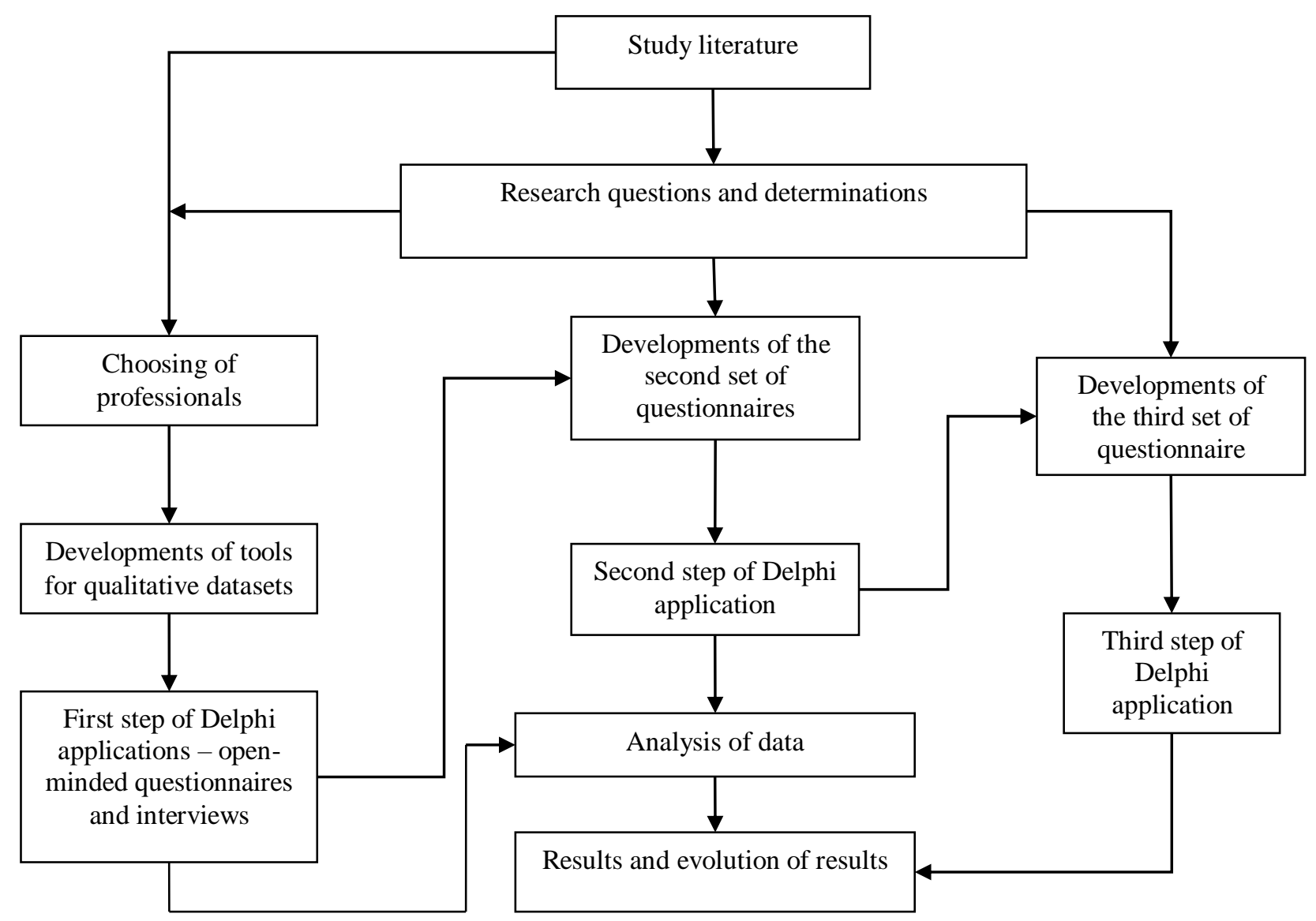

Fig 1. Process of the Delphi study

In this study, three phases of Delphi research were carried out. The qualitative data was gathered first. The quantitative form for the Delphi study's second phase was created once the data was evaluated. The ultimate quantitative formulation (for the third phase) was produced once the data obtained in the second stage was analyzed. The three stages are followed in the creation of questionnaire formats and data analysis techniques. The Delphi approach, on the other hand, obtains qualitative data during the first round, which then serves as the foundation for quantitative data in the later rounds. a representative example.

In the Delphi research, there are three stages that must be completed in order. The sample included 45 specialists who volunteered to take part in the research. These 45 professionals all hold $\mathrm{PhDs}$ in environmental science and were chosen via a purposeful sampling approach. In the $\mathrm{Eu}-(40)$, the U. S., and Africa (5), these professionals work as scholars, instructors, and instructors. In the $1^{\text {st }}, 2^{\text {nd }}$ and $3^{\text {rd }}$ stages of result, there are twenty, forty four and thirty one participants.

The average, error margin, median, variance between quarters, replies percent, consensus (cons), and consensual variance (cons. dif.) were all evaluated to see if mathematical consensus had been achieved.

\section{CRITICAL ANALYSIS}

Scope

The scope of STEM education is expanding all the time. As a result, STEM encompasses not only science and technology, but also the ecology, economy, and health [8]. The term "E+STEM literacy" is utilized in this study to underline the significance of the interaction among both environmental and STEM numeracy. The following is an example of E+STEM literacy:

- Have a fundamental understanding of environmental issues and STEM subjects;

- To have a better understanding of how environmental science is incorporated into STEM fields;

- To approach environmental concerns or problems from a multidisciplinary (STEM) perspective and try to discover solutions, to be able to analyze evidence and develop conclusions in order to form ones personal perspective.

In the years ahead, meeting the demand for an elevated Job market may require not only STEM literacy but also environment and sustainability. As a result, ecological awareness should be incorporated into both STEM disciplines and STEM education. 


\section{"Environment" in STEM}

Why is it necessary to include the idea of "Environment" in STEM learning? With the industry revolution 4.0, it is expected that innovation would advance more quickly. However, this means that the existing environmental habitats may be depleted. As a result, subsequent generations should be conscious of the importance of environmental conservation as technology develops and is used. This understanding could help to reduce household trash as well as industrial effluent, particularly waste material (e.g, electrical, waste batteries, electric materials). For instance, in Germany, the overall quantities of trash has been steadily increasing since 2012, according to reports.

Avoiding garbage from continuing to grow entails safeguarding available resources. We have a responsibility to educate subsequent generations to be ecologically responsible, taking into account the negative effects of science and technology on the ecology. As a result, the significance of "nature" in STEM learning has to be illustrated. Consequently, researchers and educators carry a major share of the responsibility, since it is critical for experts to show the significance of environmental preservation and the manner in which ecological issues can be incorporated into STEM learning throughout education systems.

\section{Pedagogical Content Knowledge (PCK)}

The growth of competent ecologically terms of capacity is influenced by the industry experience, effective teaching, and dispositions of the instructors. Generally, instructors gain experience in the industry through which was before as well as in education. Instructors' career and skills growth should be prioritized by learners so that they can easily teach and integrating sustainability topics into their lectures. It is not always possible to teach pupils with skillsets in the $21^{\text {st }}$ century without the inclusion of competent educators. Furthermore, in order to properly teach students in ecological awareness, work experience must take a multi-level strategy.

PCK also involves a grasp of what makes studying particular subjects simple or complex, such as the assumptions and biases that learners of different generations and learning experiences bring to the research of mostly-learned courses and concepts. PCK is affected by various types of knowledge: content area understanding, pedagogical content knowledge, and contextual knowledge. PCK and its structure have evolved and changed to meet the needs of the twenty-first decade and even beyond. One of the most explicit instances is technical PCK (TPCK) acknowledging the importance of integrating technology with PCK. Technology's Importance in Education (Fig 2) TPCK is an education history made up of three various knowledge modules:

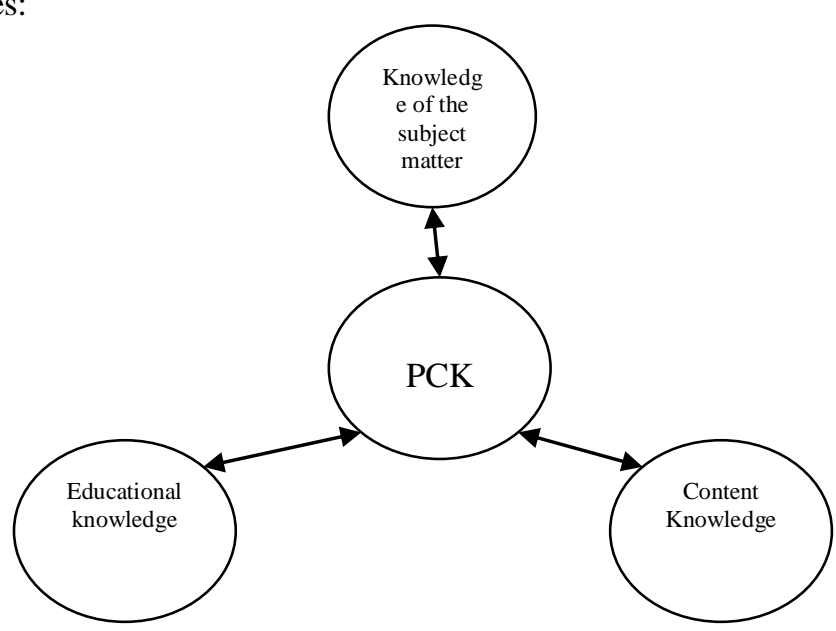

Fig 2. A framework of instructor knowledge. With this framework, educational content knowledge is considered as novel domain of knowledge.

According to Y. Hartati, A. Permanasari, W. Sopandi and A. Mudzaki in [9], technical expertise, pedagogical skills, and subject knowledge are all important. T-PCK is the foundation of successful technology-assisted learning, and it necessitates a grasp of how ideas are represented using technologies. Pedagogic methods that use technology in constructive methods for teaching content include an insight into what makes subjects difficult or simple to follow, as well as how technology may assist rectify some of the problems that students face. It takes into account learners' past understanding and epistemological ideas; furthermore, it incorporates understanding of how technology may be utilized to expand on current knowledge, establish new conceptual frameworks, or enhance existing ideas. Educators' knowledge of TPCK is essential for effective technology-assisted instruction. This is because TPCK is a useful idea for considering how technology may be integrated into the classroom and how instructors can then build this expertise . With the idea of STEM beginning to appear in the present scientific syllabus, educational stakeholders should critically think about how to incorporate STEM education into science instruction (see Fig 3).

\section{STEM into PCK}

In order to make education more available to students, educational expertise is utilized to promote successful teaching techniques. When teaching is at its best, students and teachers collaborate to achieve a common goal of understanding. Education system is one factor to consider when it comes to the efficacy of STEM education. The educational process is 
directly influenced by the quality of teacher development. One of the most important components for improving student learning is instructor subject expertise. Education systems, on the other hand, seldom integrate subject learning with methodology; moreover, if a trainee is not concentrating in a STEM-related profession, STEM material preparations in preservice learning is often insufficient. As a result, teachers are encouraged to get more STEM learning and teaching experiences, both in in-service and pre-service development. As a result, administrations promote educators'/teachers' skills and knowledge in STEM subjects via tactics such as recruiting, preparing, encourage, and maintenance.

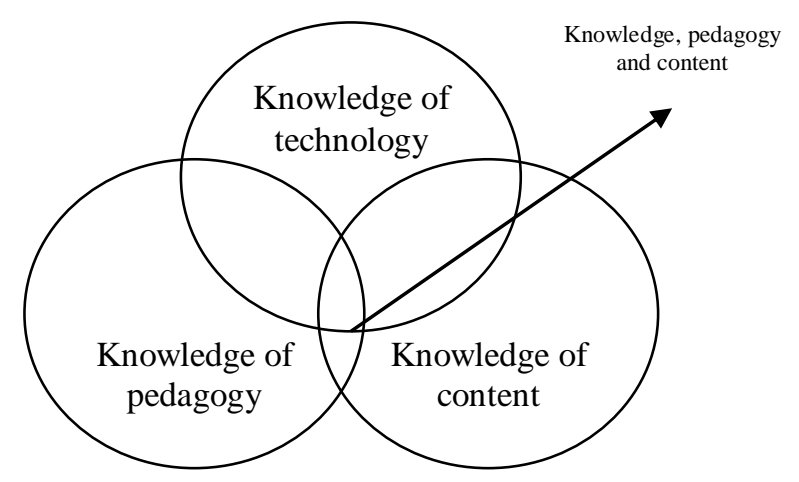

Fig 3. Knowledge, pedagogy and content of the connection between PCK and STEM has emerged in order to foster instructor's expert development

To begin, the STEM idea should be introduced into the PCK to improve the knowledge and expertise of students and administrators in STEM education. Researchers propose the notion of "STEM PCK," which focuses on students' preferences about and teaching techniques linked to STEM themes. The phrase "STEMPCK," which stands for Science, Technology, Engineering, and Mathematic PCK (Fig 4). A compacted STEM-PCK model stipulates that instructors have the required expertise to recognize and evaluate their learners' growth of STEM ideas, investigation techniques, and actual linkages, and to adjust their curriculum in constructive ways as a result.

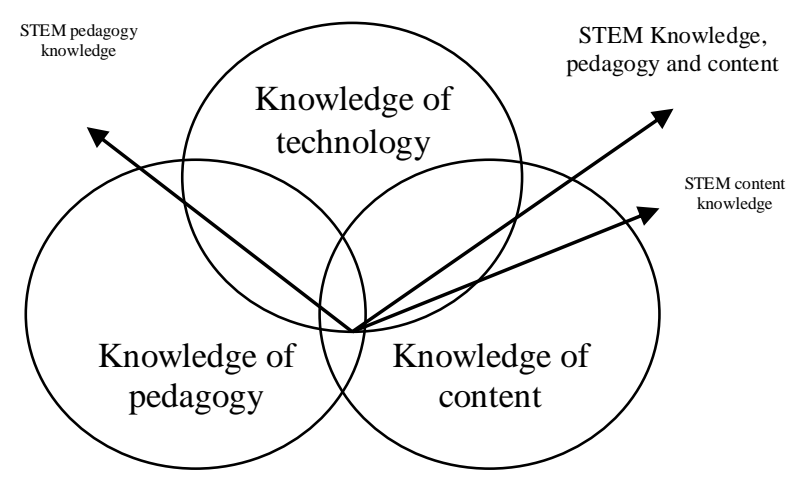

Fig 4. STEM pedagogy, content and knowlede

Thus, the integrated application of the Delphi and mixed-method approaches aid in uncovering, defining, and teaching the agreement on the best practice and particular circumstances for the study theme.

\section{RESULTS AND DISCUSSION}

The outcomes from the $1^{\text {st }}$ round were utilized in the $2^{\text {nd }}$ and $3^{\text {rd }}$ rounds. Every topic is represented by a query, and each item is represented by a symbol. Some questions were raised in the interviews and questionnaires to discover the specialists' perspectives on how instructors build their skills and credentials as E+STEM competent persons. "Teacher educators should have subject understanding about environmental concerns and practical abilities to educate about the environmental problem," the number of professionals agreed. There was agreement on six issues about how instructors should enhance their skills and credentials as E+STEM proficient professionals at the conclusion of the Delphi research. When the $2^{\text {nd }}$ and $3^{\text {rd }}$ results were differentiated, most of the educators who agreed that "educators should regularly update their knowledge about environmental challenges and follow the concept of sustainable techniques" enhanced, while the majority of teachers who agreed that "educators should pertain environmental innovation" reduced.

For the growth of skilled ecologically educated persons, educational abilities and an instructor's temperament are critical. As a result, teacher education and career development must be prioritized. There was agreement on "having and upgrading material knowledge on environmental challenges," "following the promotion of green technology, and implementing them in lesson," and based on the advancements of more sustanable remedies, and applying them in a 
classroom setting. In addition, there was also consensus on "having and growing educational competences for the growth of educators" as well as "perspectives and credentials as E+STEM literate persons" (see Fig 5).

Experts feel it is critical for educators to be well-versed in both educational and ecological expertise, as well as to keep their expertise up to date. Science instructors, in particular, should keep their PCK and skills updated in view of the growing relevance of STEM learning. A strong STEM-PCK guarantees that instructors bear the information they need to recognize and track their pupils' progress in STEM topics. Educators that participate in STEM-PCK develop understanding of both the environmental and STEM, as well as experiences integrating the two ideas [10]. As a result, scientific education may be able to satisfy the aspirations of current and future generations.

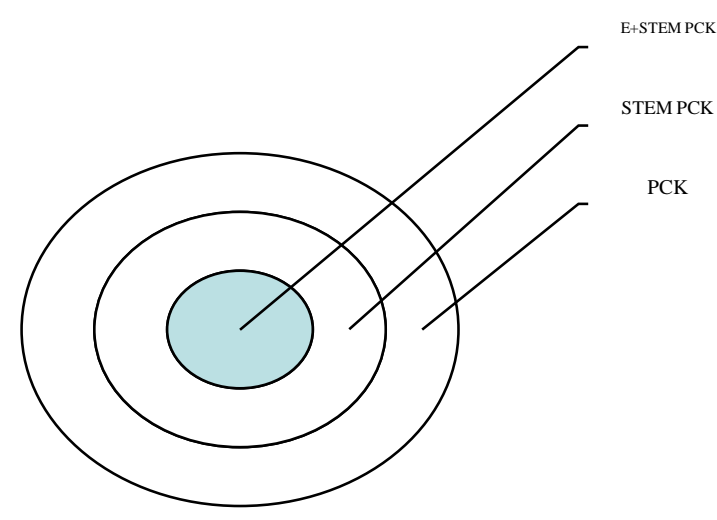

Fig 5. Incorporation of the environmental intoo STEM pedagogical knowledge content

\section{CONCLUSION AND FUTURE RESEARCH}

The findings indicate that professional growth is an imperative aspect of E+STEM intellectual people. As a result, trained E+STEM-educated people need competent E+STEM-educated instructors. Environmental education has to be integrated in educational programmes at colleges. The notion of "environment" particularly needs incorporation into STEM-PCK paradigm for teaching and learning. E+STEM PCK assessment comprises 3 distinct knowledge elements:

- $\quad$ E+STEM learning of content (understanding of STEM and the ecosystem)

- Didactic awareness, i.e., knowledge about how to instruct STEM tasks linked to the ecosystem

- E+STEM-Knowledge refers to the interdisciplinary knowledge needed for the inclusion of STEM as ecologically responsible, as well as extra knowledge about the connection between the ecosystem and the STEM topics to be addressed.

This would include incorporating an innovative pedagogical and ecological paradigm, E+STEM-PCK, into education systems. The breadth of E+STEMPCK in view of the PCK and STEM-PCK frameworks, as well as how it may be taught to teachers, may then be determined in future study, thus enhance the effectiveness of STEM. Furthermore, the notion of "environment" ought to be included into the paradigm of STEM training, enabling for the growth of environmentallyaware STEM literacy (E+STEM) in scientific courses and curriculum.

\section{References}

[1]. D. Carlisle and G. Weaver, "STEM education centers: catalyzing the improvement of undergraduate STEM education", International Journal of STEM Education, vol. 5, no. 1, 2018. Doi: 10.1186/s40594-018-0143-2.

[2]. T. HIGUCHI, "Directions of Research on Knowledge and Ability for Environmental Education Among Schoolteachers in Japan", Environmental Education, vol. 19, no. 2, pp. 19-20, 2009. Doi: 10.5647/jsoee.19.2_19.

[3]. R. Chepesiuk, "Environmental Literacy: Knowledge for a Healthier Public", Environmental Health Perspectives, vol. 115, no. 10, 2007. Doi: 10.1289/ehp.115-a494.

[4]. M. Morrone, K. Mancl and K. Carr, "Development of a Metric to Test Group Differences in Ecological Knowledge as One Component of Environmental Literacy", The Journal of Environmental Education, vol. 32, no. 4, pp. 33-42, 2001. Doi: 10.1080/00958960109598661.

[5]. S. Jorgenson, "Green pedagogy: How STEM teachers understand and enact environmental projects", Environmental Education Research, vol. 22, no. 3, pp. 452-453, 2015. Doi: 10.1080/13504622.2015.1118753.

[6]. F. Stewart, "STEM and the Local Economy: Do Regions Reap the Benefits of a STEM-Educated Workforce?", Employment Research, vol. 25, no. 1, pp. 1-4, 2018. Doi: 10.17848/1075-8445.25(1)-1.

[7]. O. Laserina, "Progressing Quality Care Process Metrics for Public Health Nursing: Viewed Through the Lens of a Modified Delphi Approach", Nursing \& Healthcare International Journal, vol. 4, no. 5, 2020. Doi: 10.23880/nhij-16000229.

[8]. M. Rupp, "Tracking Science: Following the STEM Trend", Science Scope, vol. 037, no. 06, 2014. Doi: 10.2505/4/ss14_037_06_54.

[9]. Y. Hartati, A. Permanasari, W. Sopandi and A. Mudzakir, "Relationship between content knowledge and general pedagogical knowledge on pedagogical content knowledge", Journal of Physics: Conference Series, vol. 1157, p. 042045, 2019. Doi: 10.1088/1742-6596/1157/4/042045.

[10]. J. Kim and Y. Yoon, "A Study on PCK of Educators for the Educational System of Line Dance: Differentiation of Pedagogical Content Knowledge by Students Educated", Journal of Sport and Leisure Studies, vol. 48, pp. 87-102, 2012. Doi: 10.51979/kssls.2012.05.48.87. 